\title{
Enhanced intracellular delivery and controlled drug release of magnetic PLGA nanoparticles modified with transferrin
}

\author{
Yan-na CUI ${ }^{1,2,3}$, Qing-xing XU ${ }^{1}$, Pooya DAVOODI ${ }^{1}$, De-ping WANG ${ }^{2, *}$, Chi-Hwa WANG ${ }^{1, *}$ \\ ${ }^{1}$ Department of Chemical and Biomolecular Engineering, National University of Singapore, Singapore 117585, Singapore; ${ }^{2}$ School of \\ Materials Science and Engineering, Tongji University, Shanghai 201804, China; ${ }^{3}$ Key Laboratory of Primate Neurobiology, Institute of \\ Neuroscience, Shanghai Institute for Biological Sciences, Chinese Academy of Sciences, Shanghai 200031, China
}

\begin{abstract}
Owing to the presence of multidrug resistance in tumor cells, conventional chemotherapy remains clinically intractable. To enhance the therapeutic efficacy of chemotherapeutic agents, targeting strategies based on magnetic polymeric nanoparticles modified with targeting ligands have gained significant attention in cancer therapy. In this study, we synthesized transferrin (Tf)-modified poly( $D$, Llactic-co-glycolic acid) nanoparticles (PLGA NPS) loaded with paclitaxel (PTX) and superparamagnetic nanoparticle (MNP) using a solidin-oil-in-water solvent evaporation method, followed by Tf adsorption on the surface of NPs. The Tf-modified magnetic PLGA NPs were characterized in terms of particle morphology and size, magnetic properties, encapsulation efficiency and drug release. Furthermore, the cytotoxicity and cellular uptake of the drug-loaded magnetic PLGA NPs were evaluated in both MCF-7 breast cancer and U-87 glioma cells in vitro. We found that Tf-modified PTX-MNP-PLGA NPs showed the highest cytotoxicity effect and cellular uptake efficiency under Tf receptor mediation in both MCF-7 and U-87 cells compared to unmodified PLGA NPs and free PTX. The cellular uptake efficiency of Tf-modified magnetic PLGA NPs appeared to be facilitated by the applied magnetic field, but the difference did not reach statistical significance. This study illustrates that this proposed formulation can be used as one new alternative treatment for patients bearing inaccessible tumors.
\end{abstract}

Keywords: magnetic nanoparticle; transferrin receptors; paclitaxel; targeted drug delivery; MCF-7 breast cancer; U-87 glioma cells; nanomedicine

Acta Pharmacologica Sinica (2017) 38: 943-953; doi: 10.1038/aps.2017.45; published online 22 May 2017

\section{Introduction}

With the advent of novel chemotherapeutic drugs, chemotherapy has been widely used to inhibit tumor growth and metastasis in cancer patients ${ }^{[1,2]}$. For instance, paclitaxel (PTX) is a mitotic inhibitor and is used to treat a variety of solid tumors involving the brain, breast, lung, bladder, and ovary ${ }^{[3-7]}$. However, the potential of these novel drugs is often limited by the severe toxicity imposed on normal tissues of the body resulting from their systemic delivery and the multidrug resistance (MDR) in tumor cells that can extrude drugs using transporter proteins $^{[8,9]}$.

The use of biocompatible and biodegradable poly $(D, L-$ lactic-co-glycolic acid) nanoparticles (PLGA NPs) as a drug

\footnotetext{
* To whom correspondence should be addressed.

E-mail chewch@nus.edu.sg (Chi-Hwa WANG); wdpshk@tongji.edu.cn (De-ping WANG)

Received 2016-11-18 Accepted 2017-04-05
}

delivery system has been widely investigated for various biomedical applications, particularly for cancer treatment ${ }^{[10]}$. PLGA NPs are advantageous in terms of their sustained release property, protection of the drug from degradation and well-described formulations to deliver various therapeutics with favorable drug release profiles ${ }^{[11,12]}$. PLGA NPs are not affected by cell membrane-associated efflux transporters since the drug is well encapsulated. It is expected that these NPs could escape the efflux action of these transporters and lead to greater cellular uptake than free drug formulations. In addition, once the NPs enter cancer cells, intracellular release of the drug in a controlled manner can preserve the drug effect and improve the therapeutic efficiency.

Magnetic nanoparticle (MNP) can become magnetic in a magnetic field and lose this magnetism after the magnetic field is removed ${ }^{[13]}$. Although this form of the superparamagnetic property has been extensively exploited in bio-imaging, chemotherapeutic drugs can also be directed toward a specific tis- 
sue by applying a magnetic field ${ }^{[14,15]}$. Thus, the incorporation of MNP into PLGA NPs can enhance the delivery of drugs to a target site in the body while reducing systemic toxicity and increasing drug efficacy ${ }^{[16]}$.

In addition, the conjugation of targeting moieties, such as peptides, proteins and aptamers ${ }^{[17-19]}$, to polymeric carriers could offer an effective approach to target drugs to tumor cells $^{[20]}$. Transferrin (Tf), an iron-binding plasma glycoprotein, is crucial for the cellular transport of iron mediated by cell surface Tf receptors, and such receptors have been found to be overexpressed in proliferating cancer cells compared to normal tissues. Cell surface Tf receptors can bind diferric Tf (holo-Tf) with high affinity, and Tf-modified PLGA NPs can be internalized through receptor-mediated endocytosis ${ }^{[21]}$.

The aim of this study is to explore the feasibility of drugand MNP-loaded PLGA NPs modified with Tf to enhance cellular uptake and improve therapeutic efficiency in cancer cells. PTX was selected as the model antiproliferative drug to load into PLGA NPs. PLGA NPs were synthesized and characterized in terms of particle morphology and size, magnetic properties, encapsulation efficiency and drug release. Unlike previously developed Tf-conjugated PLGA NPs ${ }^{[22-25]}$, here, we have employed an adsorption technique for the functionalization of NPs without covalent grafting. Finally, the cytotoxicity and cellular uptake of the drug-loaded PLGA NPs were evaluated in vitro in MCF-7 breast cancer and U-87 glioma cells.

\section{Materials and methods Materials}

Ammonium hydroxide $\left(\mathrm{NH}_{3} \cdot \mathrm{H}_{2} \mathrm{O}, 28 \%-30 \%\right)$, iron (III) chloride hexahydrate $\left(\mathrm{FeCl}_{3} \cdot 6 \mathrm{H}_{2} \mathrm{O}, 98 \%\right)$, human holo-transferrin $(\geq 98 \%)$, sodium sulfite $\left(\mathrm{Na}_{2} \mathrm{SO}_{3}, \geq 98 \%\right)$, poly(vinyl alcohol) (PVA, $\mathrm{M}_{\mathrm{W}}=30-70 \mathrm{kDa}$ ), dichloromethane (DCM), zinc sulfate monohydrate $\left(\mathrm{ZnSO}_{4} \cdot \mathrm{H}_{2} \mathrm{O}\right)$, coumarin-6 (CM), hydrochloric acid $(\mathrm{HCl})$, oleic acid $(\mathrm{OA}, \geq 99 \%)$, acetonitrile $(\mathrm{ACN}, \geq 99.5 \%)$, calcium chloride dihydrate $\left(\mathrm{CaCl}_{2} \cdot 2 \mathrm{H}_{2} \mathrm{O}\right)$, potassium chloride $(\mathrm{KCl})$, magnesium sulfate $\left(\mathrm{MgSO}_{4}\right)$, monobasic sodium phosphate $\left(\mathrm{NaH}_{2} \mathrm{PO}_{4}\right)$, sodium chloride $(\mathrm{NaCl})$, 4-(2-hydroxyethyl) piperazine-1-ethanesulfonic acid (HEPES) and D-glucose were obtained from Sigma-Aldrich Corp (St Louis, MO, USA). PLGA 50:50 (inherent viscosity=0.24-0.54 dL/g in hexafluoroisopropanol) was purchased from Lactel Absorbable Polymers (Pelham, AL, USA). The CellTiter $96^{\circledR}$ Non-Radioactive Cell Proliferation Assay was purchased from Promega Corp (Madison, WI, USA). Phosphate-buffered saline (PBS, $\mathrm{pH}=7.4$ ) was purchased from Mediatech, Inc (Manassas, VA, USA). Paclitaxel (PTX) was kindly supplied by Bristol-Myers Squibb Company (New York, NY, USA) at no cost.

\section{Preparation of oleic acid-modified magnetic nanoparticle (OA-} MNP)

MNP was prepared with reference to the protocol reported in the previous work ${ }^{[26]}$. Briefly, $\mathrm{FeCl}_{3}(8 \mathrm{~mL}, 1 \mathrm{~mol} / \mathrm{L}), \mathrm{Na}_{2} \mathrm{SO}_{3}$ $(1.5 \mathrm{~mL}, 1 \mathrm{~mol} / \mathrm{L})$ and $\mathrm{NH}_{3} \cdot \mathrm{H}_{2} \mathrm{O}(5 \mathrm{~mL}, 28 \%-30 \%)$ solutions were added to $100 \mathrm{~mL}$ of deionized water and heated with stirring under nitrogen at $70-80{ }^{\circ} \mathrm{C}$ for $30 \mathrm{~min}$. While heating,
$0.33 \mathrm{~mL}$ of OA was added to modify the surface of MNP with OA before further incubating the mixture at $80^{\circ} \mathrm{C}$ for $50 \mathrm{~min}$. The temperature was then raised to $110^{\circ} \mathrm{C}$ to evaporate excess ammonium hydroxide and water. Finally, $\mathrm{HCl}$ was added to precipitate the MNP. The oleic acid-modified MNP (OAMNP) was removed from the solution using a magnet, washed repeatedly with acetone and deionized water and lyophilized to obtain the powder.

\section{Preparation of PTX- and MNP-loaded PLGA NPs (PTX-MNP-PLGA NPs)}

PTX- and MNP-loaded PLGA NPs (PTX-MNP-PLGA NPs) were prepared according to the protocol reported in previous studies $^{[27,28]}$. Briefly, $20 \mathrm{mg}$ of PTX and $100 \mathrm{mg}$ of PLGA were dissolved in $1 \mathrm{~mL}$ of DCM. Varying amounts of OA-MNP were added to the solution, and the mixture was sonicated using a microtip probe sonicator (VC 505, Sonics \& Materials, Inc, Newtown, CT, USA) at 25\% amplitude for $1 \mathrm{~min}$. Following that, the mixture was combined with PVA $(2 \mathrm{~mL}, 2 \%$ or $4 \%(w / v)$ in water) and sonicated for another 1 min. After that, the mixture was dropwise added into more PVA solution ( $48 \mathrm{~mL}, 0.05 \%(w / v)$ in water) and stirred for $24 \mathrm{~h}$ to ensure complete evaporation of the organic solvent. The samples were washed repeatedly with deionized water and lyophilized. CM- and MNP-loaded PLGA NPs (CM-MNP-PLGA NPs) were also prepared in a similar manner by loading $0.05 \%$ $(w / w)$ CM in PLGA. MNP-loaded PLGA NPs (MNP-PLGA NPs) were also synthesized in a similar manner without the addition of any drug.

Preparation of Tf-modified PTX- and MNP-loaded PLGA NPs (Tfmodified PTX-MNP-PLGA NPs)

Tf-modified PTX- and MNP-loaded PLGA NPs (Tf-modified PTX-MNP-PLGA NPs) were prepared based on a reported procedure $^{[25,29,30]}$. Tf solutions were first prepared in RingerHepes buffer ( $\mathrm{pH}=7.4$, containing $1.8 \mathrm{mmol} / \mathrm{L} \mathrm{CaCl}_{2}, 5.6$ $\mathrm{mmol} / \mathrm{L} \mathrm{KCl}, 0.8 \mathrm{mmol} / \mathrm{L} \mathrm{MgSO}_{4}, 0.8 \mathrm{mmol} / \mathrm{L} \mathrm{NaH}_{2} \mathrm{PO}_{4}$, $116 \mathrm{mmol} / \mathrm{L} \mathrm{NaCl}, 25 \mathrm{mmol} / \mathrm{L} \mathrm{HEPES}$ and $5.5 \mathrm{mmol} / \mathrm{L}$ $D$-glucose) at different concentrations ranging from 0.2 to 1.0 $\mathrm{mg} / \mathrm{mL}$. Then, $30 \mathrm{mg}$ of PTX-MNP-PLGA NPs was added to the above solutions, and the samples were moderately shaken at room temperature for $3 \mathrm{~h}$. Lastly, the sample was ultra-filtered to remove free Tf, washed and lyophilized. Tfmodified CM-MNP-PLGA NPs were also prepared in a similar manner. The amount of Tf adsorbed on the surface of PLGA NPs was determined using a BCA Protein Assay Kit (Thermo Fisher Scientific, Inc, Rockford, IL, USA).

\section{Characterization of PLGA NPs}

The PLGA NPs were characterized by visualizing their morphology via transmission electron microscopy (TEM, Tecnai G2 F20, FEI Company, Hillsboro, OR, USA) with a resolution of $0.14 \mathrm{~nm}$ for lattice images and $0.25 \mathrm{~nm}$ for point images, measuring their hydrodynamic size via dynamic light scattering (DLS, 90Plus Particle Size Analyzer, Brookhaven Instruments Corp, Holtsville, NY, USA), analyzing their magnetic 
properties via vibrating sample magnetometry (VSM, EV7, MicroSense, LLC, Lowell, MA, USA), and examining their thermal stability via thermogravimetric analysis (TGA, DTG$60 \mathrm{H}$, Shimadzu Corp, Kyoto, Japan). The surface functional groups of the samples were analyzed by Fourier transform infrared spectroscopy (FTIR, Excalibur FTS 3500GX, Bio-Rad Laboratories, Inc, Cambridge, MA, USA).

\section{Encapsulation efficiency}

The encapsulation efficiency of PTX in PLGA NPs was determined by high-performance liquid chromatography (HPLC, 1200 Series, Agilent Technologies, Inc, Santa Clara, CA, USA). Briefly, $2 \mathrm{mg}$ of sample was dissolved in $1 \mathrm{~mL}$ of DCM to extract PTX from PLGA NPs in triplicate. After solvent evaporation, the residue was re-dissolved in $1 \mathrm{~mL}$ of mobile phase (70:30 ACN to $\mathrm{H}_{2} \mathrm{O}$ ratio), and the solution was filtered through a $0.2-\mu \mathrm{m}$ syringe filter before analysis by HPLC using a C18 column. The mobile phase was delivered at a rate of $1 \mathrm{~mL} / \mathrm{min}$. A total of $100 \mu \mathrm{L}$ of the sample was injected by an auto-sampler, and the column effluent was measured at $227 \mathrm{~nm}$ using an ultraviolet (UV) detector. The column was maintained at $25^{\circ} \mathrm{C}$. PTX samples of standard concentrations were used to produce the calibration plot. The encapsulation efficiency of PTX was calculated as the percentage of the initial amount of PTX used that was entrapped in the PLGA NPs.

\section{In vitro drug release}

For each batch of PTX-MNP-PLGA NPs, approximately 10 $\mathrm{mg}$ of sample was suspended in $20 \mathrm{~mL}$ of PBS with $0.05 \%$ $(w / v)$ Tween 80 in triplicate. The samples were incubated at $37^{\circ} \mathrm{C}$ and continuously shaken at 150 rounds per minute. The supernatant was removed at designated time points and replaced with fresh PBS to maintain constant $\mathrm{pH}$ and sink conditions. To determine the amount of PTX, the drug was extracted from the supernatant using DCM. After the DCM was evaporated, the residue was re-dissolved in $1 \mathrm{~mL}$ of mobile phase (70:30 ACN to $\mathrm{H}_{2} \mathrm{O}$ ratio). Finally, the solution was filtered through a $0.2-\mu \mathrm{m}$ syringe filter before analyzing with HPLC.

\section{Cell culture and maintenance}

MCF-7 is a breast cancer cell line (ATCC Number: HTB-22 ${ }^{\mathrm{TM}}$ ) derived from a 69-year-old Caucasian woman. U-87 MG is a glioblastoma, astrocytoma cell line (ATCC Number: HTB-14 ${ }^{\mathrm{TM}}$ ) derived from the malignant glioma of a 44-year-old Caucasian man. All cells were incubated at $37^{\circ} \mathrm{C}$ and $5 \% \mathrm{CO}_{2}$. The medium used for cell culture was Dulbecco's modified Eagle's medium (DMEM) (Gibco, Life Technologies Corp, Carlsbad, CA, USA) supplemented with $1 \%$ penicillin-streptomycin (PS) (PAN-Biotech GmbH, Aidenbach, Germany) and $10 \%$ fetal bovine serum (FBS) (HyClone, Thermo Fisher Scientific, Inc, Logan, UT, USA).

\section{In vitro cytotoxicity}

The cytotoxic effects of Tf-modified PTX-MNP-PLGA NPs, Tfmodified PTX-MNP-PLGA NPs with free Tf, PTX-MNP-PLGA
NPs and free PTX were examined in MCF-7 and U-87 cells. Briefly, cells were cultured in $96-$ well plates at $5 \times 10^{3}$ cells per well for $24 \mathrm{~h}$ before treating them with different concentrations of Tf-modified PTX-MNP-PLGA NPs, Tf-modified PTXMNP-PLGA NPs with free Tf, PTX-MNP-PLGA NPs and free PTX. For Tf-modified PTX-MNP-PLGA NPs with free Tf, free Tf was added together with the drug-loaded NPs to the cells. The cell viability was then measured 24 and $96 \mathrm{~h}$ after treatment using a CellTiter $96^{\circledR}$ Non-Radioactive Cell Proliferation Assay (Promega Corp, Madison, WI, USA). The cells were rinsed with PBS before adding $100 \mu \mathrm{L}$ of fresh culture medium and $15 \mu \mathrm{L}$ of dye solution. The plates were further incubated for $4 \mathrm{~h}$. Then, $100 \mu \mathrm{L}$ of solubilization solution was added to the cells, and the plates were gently shaken at room temperature for $24 \mathrm{~h}$. The absorbance of the sample was measured with six replicates using a spectrophotometer at $570 \mathrm{~nm}$ with a reference wavelength of $630 \mathrm{~nm}$.

\section{Internalization pathway of nanoparticles Qualitative intracellular uptake study}

For the qualitative study tracking the cellular uptake of drugloaded PLGA NPs, cells were cultured in 24-well plates with glass cover slips at $5 \times 10^{4}$ cells per well for $24 \mathrm{~h}$ before they were treated with Tf-modified CM-MNP-PLGA NPs, Tf-modified CM-MNP-PLGA NPs with free Tf, CM-MNP-PLGA NPs or free $\mathrm{CM}$ at a concentration of $100 \mu \mathrm{g} / \mathrm{mL}$. The cells were then prepared for confocal imaging 2 and $8 \mathrm{~h}$ after treatment. The cells were rinsed with PBS and fixed with a 70\% cold ethanol solution at room temperature for $20 \mathrm{~min}$. The cells were then rinsed with PBS three times before staining with Hoechst dye $(1 \mu \mathrm{g} / \mathrm{mL})$ for $45 \mathrm{~min}$. Finally, the cells were again rinsed with PBS three times. The cover slips with attached cell monolayers were inverted with the cell layer face down onto microscope slides and visualized using a Fluoview FV1000 laser scanning confocal microscope (Olympus Corp, Tokyo, Japan), with the corresponding confocal images captured by Olympus Fluoview software.

\section{Quantitative intracellular uptake study}

For the quantitative study to determine the intracellular $\mathrm{CM}$ level from the cellular uptake of drug-loaded PLGA NPs, cells were cultured in 24 -well plates at $5 \times 10^{4}$ cells per well for $24 \mathrm{~h}$ before treating them with Tf-modified CM-MNP-PLGA NPs with a magnetic field, Tf-modified CM-MNP-PLGA NPs, Tfmodified CM-MNP-PLGA NPs with free Tf, CM-MNP-PLGA NPs or free $\mathrm{CM}$ at a concentration of $100 \mu \mathrm{g} / \mathrm{mL}$. For Tfmodified CM-MNP-PLGA NPs with a magnetic field, the cells treated with drug-loaded PLGA NPs were subjected to $0.1 \mathrm{~T}$ neodymium-iron-boron permanent magnets (Master Magnetics, Inc, Castle Rock, CO, USA) placed externally under each well. Following 2 and $8 \mathrm{~h}$ of treatment, the cells were rinsed with PBS, lysed with $200 \mu \mathrm{L}$ of $0.5 \%(w / w)$ Triton-X 100 in 0.2 $\mathrm{mol} / \mathrm{L} \mathrm{NaOH}$ solution ${ }^{[3]}$, and shaken for $15 \mathrm{~min}$. The fluorescence intensity of the sample was measured by a microplate reader at excitation and emission wavelengths of 430 and $505 \mathrm{~nm}$, respectively. The fractional amount of $\mathrm{CM}$ within 
the cells was calculated as the amount of CM within the cells (fluorescence intensity) divided by the total amount of $\mathrm{CM}$ (fluorescence intensity of the sample from the known NP concentration under the same conditions of cell incubation but without washing the cells with PBS).

For the quantitative study on determining the intracellular PTX level from the cellular uptake of drug-loaded PLGA NPs, cells were cultured in 24-well plates at $5 \times 10^{4}$ cells per well for $24 \mathrm{~h}$ before treating them with Tf-modified PTX-MNP-PLGA NPs with a magnetic field, Tf-modified PTX-MNP-PLGA NPs, Tf-modified PTX-MNP-PLGA NPs with free Tf, PTX-MNPPLGA NPs or free PTX at a concentration of $100 \mu \mathrm{g} / \mathrm{mL}$. Following 2 and $8 \mathrm{~h}$ of treatment, the medium from each well was collected. Cells were rinsed with PBS to remove surfacebound PLGA NPs or free PTX, and the PBS was also collected. The two solutions were combined, and $\mathrm{ZnSO}_{4}$ was added to precipitate the protein. The suspension was vortexed for 5 min before adding DCM to extract PTX. The mixture was vortexed and kept at room temperature for $1 \mathrm{~h}$. The DCM was evaporated before re-dissolving the drug in $1 \mathrm{~mL}$ of mobile phase (70:30 ACN to $\mathrm{H}_{2} \mathrm{O}$ ratio). The solution was then filtered through a $0.2-\mu \mathrm{m}$ syringe filter before analysis with HPLC to evaluate the amount of PTX that was not taken up by the cells (A). Cells were treated with trypsin, extracted, and centrifuged at 5000 rounds per minute for $15 \mathrm{~min}$. The supernatant was removed, and $\mathrm{ZnSO}_{4}$ was added to it. DCM was then added to extract PTX. The DCM was evaporated before re-dissolving the drug in the mobile phase. The solution was then filtered and analyzed using HPLC to evaluate the amount of PTX within the cells (B). The fractional amount of PTX within the cells $(X)$ was calculated as the amount of PTX within the cells (B) divided by the total amount of PTX (A+B).

\section{Results}

\section{Morphology of MNP-PLGA NPs}

TEM images of MNP-PLGA NPs with different loadings of OA-MNP are shown in Figure 1. OA-MNP had been successfully encapsulated into PLGA with 5\% OA-MNP or less (Figure $1 \mathrm{~A}, 1 \mathrm{~B}$ and $1 \mathrm{C}$ ) through hydrophobic interactions using the solid-in-oil-in-water solvent evaporation method. By contrast, the PLGA NPs loaded with 15\% OA-MNP showed significant aggregation of MNP, which could be attributed to a higher loading amount and a stronger magnetic interaction between iron oxides (Figure 1D with insert). The MNP-PLGA NPs were nearly spherical with an average size of approximately $150 \pm 20 \mathrm{~nm}$. When the Tf concentration used was 1.0 $\mathrm{mg} / \mathrm{mL}$, the average size of Tf-modified PLGA NPs measured by DLS was approximately $464.6 \mathrm{~nm}$ with a polydispersity index of 0.057 (Figure 2D). This formulation will be used for in vitro studies. The zeta potentials were $-28.07 \pm 1.59 \mathrm{mV}$ and $-20.10 \pm 1.26 \mathrm{mV}$ for the MNP-PLGA and Tf-modified MNPPLGA NPs, respectively. To study their stability, the changes in the zeta potentials of these NPs incubated in PBS ( $\mathrm{pH} 7.2)$ were measured a few times over $96 \mathrm{~h}$. The results indicated that the zeta potentials of MNP-PLGA NPs with and without Tf were stable, though there was a decrease after modification
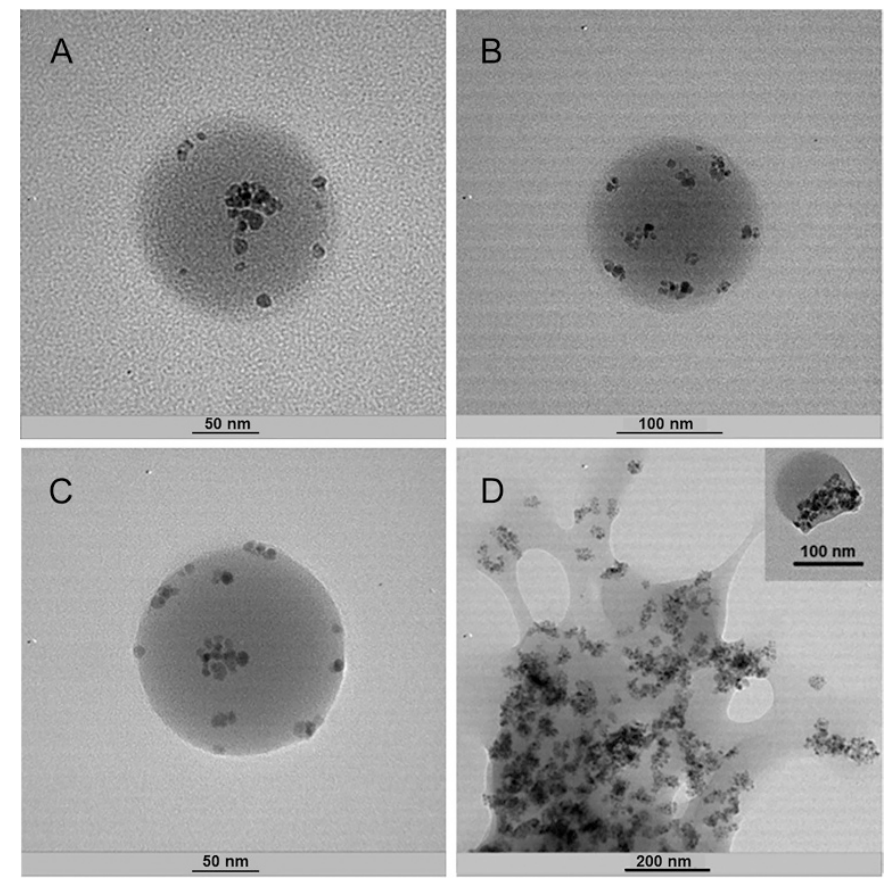

Figure 1. TEM images of MNP-PLGA NPS: (A) 1.5\% OA-MNP-PLGA NPS, 2\% PVA; (B) 5\% OA-MNP-PLGA NPs, 2\% PVA; (C) 5\% OA-MNP-PLGA NPs, 4\% PVA; (D) 15\% OA-MNP-PLGA NPs, 2\% PVA, inset: one representative photograph of the particle.

with Tf (data not shown).

\section{Magnetic properties of MNP-PLGA NPs}

To investigate the magnetic properties of MNP-PLGA NPs, magnetization measurements were made using a VSM. The curves in Figure 2A to $2 \mathrm{C}$ showed no remnant magnetic field and coercivity, indicating the presence of superparamagnetism in all the samples. The saturation magnetization $(M s)$ values of MNP, OA-MNP and MNP-PLGA NPs were 88.03, 81.99 and $10.85 \mathrm{emu} / \mathrm{g}$, respectively (Figure 2A). The Ms value of as-synthesized $\mathrm{Fe}_{3} \mathrm{O}_{4}$ was $92 \mathrm{emu} / \mathrm{g}$ ( $95 \%$ of its bulk value), which might be due to its high specific surface area ${ }^{[32]}$. Owing to the non-magnetic nature of OA and PLGA, the Ms values of OA-MNP and MNP-PLGA NPs were lower than that of MNP (Figure 2A). The Ms value of MNP-PLGA NPs increased with MNP loading in PLGA (Figure 2B). After MNP-PLGA NPs were modified with Tf, the Ms value (Figure 2C) was still higher than the reported value of $2 \mathrm{emu} / \mathrm{g}^{[33]}$.

\section{TGA thermograms of MNP-PLGA NPs}

Figure 3A shows the TGA thermograms of MNP, OA-MNP, MNP-PLGA NPs and Tf-modified MNP-PLGA NPs. The TGA thermogram of MNP showed approximately $2 \%$ weight loss from 20 to $700^{\circ} \mathrm{C}$, possibly because of the loss of surface hydroxyl groups from the MNP. For OA-MNP, approximately $5.5 \%$ weight loss was observed in the first stage from 20 to $320^{\circ} \mathrm{C}$ because of the loss of surface hydroxyl groups, while approximately $9 \%$ weight loss was observed in the sec- 

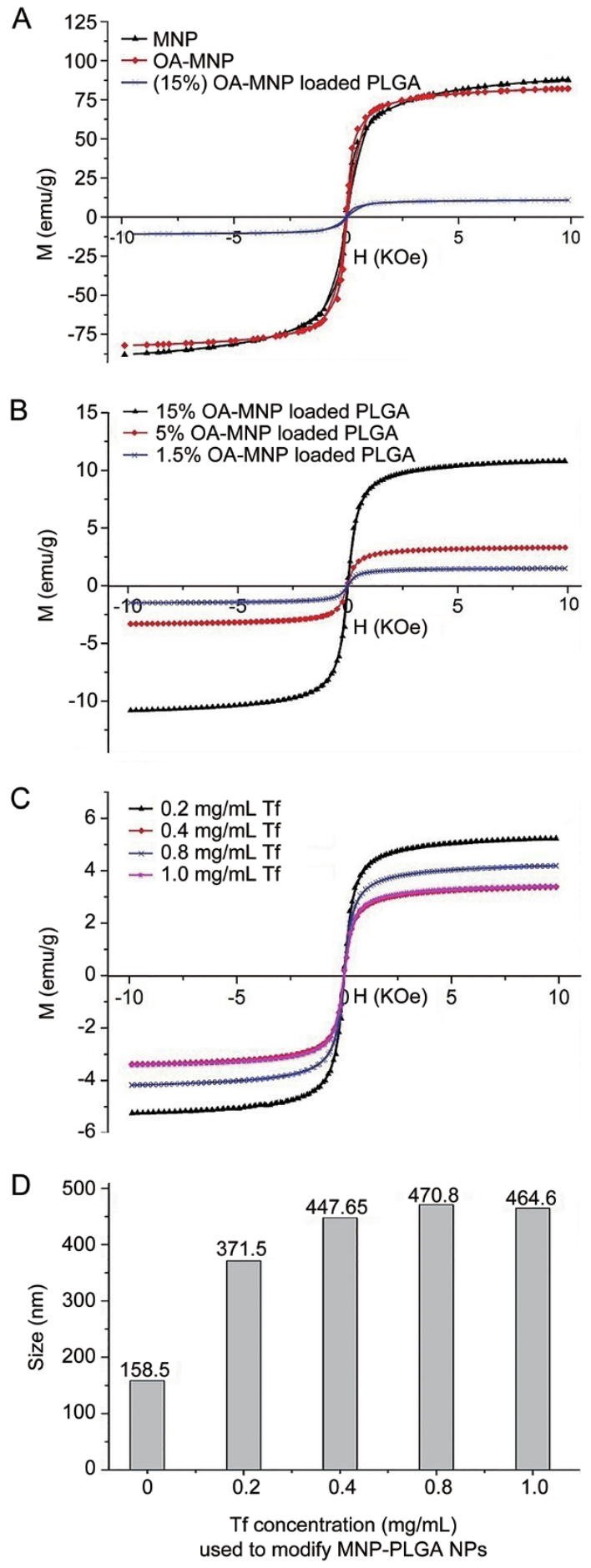

Figure 2. (A-C) Magnetization (M) curves measured under applied magnetic field $(\mathrm{H})$ at $300 \mathrm{~K}$, and $(\mathrm{D})$ hydrodynamic diameter of Tf-modified MNP-PLGA NPs synthesized from increasing Tf concentration.

ond stage from 320 to $520^{\circ} \mathrm{C}$ because of the removal of the $\mathrm{OA}$ monolayer from the OA-MNP. The weight loss profiles for MNP and OA-MNP were consistent with reported results ${ }^{[27,32]}$. The TGA thermogram of MNP-PLGA NPs showed approximately $94.3 \%$ weight loss from 250 to $400^{\circ} \mathrm{C}$, possibly because of the loss of surface hydroxyl groups and OA and to PLGA
A
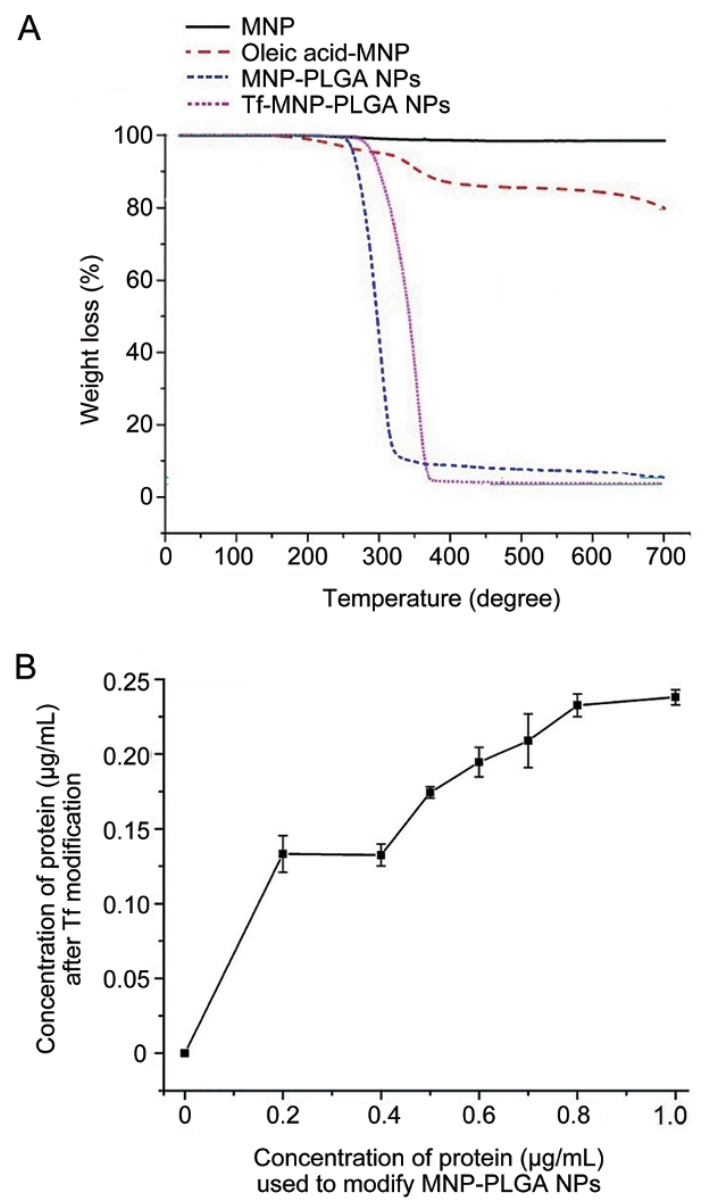

Figure 3. (A) TGA thermograms of MNP, OA-MNP, MNP-PLGA NPs and Tfmodified MNP-PLGA NPs, and (B) Surface concentration of adsorbed Tf on the surface of MNP-PLGA NPs with different concentrations of added Tf using BCA Protein Assay Kit.

degradation. Since a total of approximately $14.5 \%$ weight loss was observed for OA-MNP, the remaining $79.8 \%$ weight loss could arise from PLGA degradation. The TGA thermogram of Tf-modified MNP-PLGA NPs showed a weight loss of approximately $96.3 \%$. The difference in weight loss between the MNP-PLGA NPs and Tf-modified MNP-PLGA NPs could be associated with the presence of Tf on the surface of the PLGA NPs.

The presence of Tf on the surface of PLGA NPs was determined using a BCA Protein Assay Kit (Figure 3B). Here, Tf solutions of various concentrations, ranging from 0 to 1.0 $\mathrm{mg} / \mathrm{mL}$, were prepared and used to modify MNP-PLGA NPs. Successful modification of PLGA NPs with Tf was apparent based on the increased absorbance reading for Tf-modified MNP-PLGA NPs prepared with increased Tf concentrations.

\section{FTIR spectra of MNP-PLGA NPs}

Figure 4 shows the FTIR spectra of MNP, OA-MNP and MNP-PLGA NPs. For MNP, the absorption band observed at $582 \mathrm{~cm}^{-1}$ may be attributed to Fe-O. The absorption band at $3412 \mathrm{~cm}^{-1}$ is the characteristic band for $\mathrm{O}-\mathrm{H}$ vibrations and 

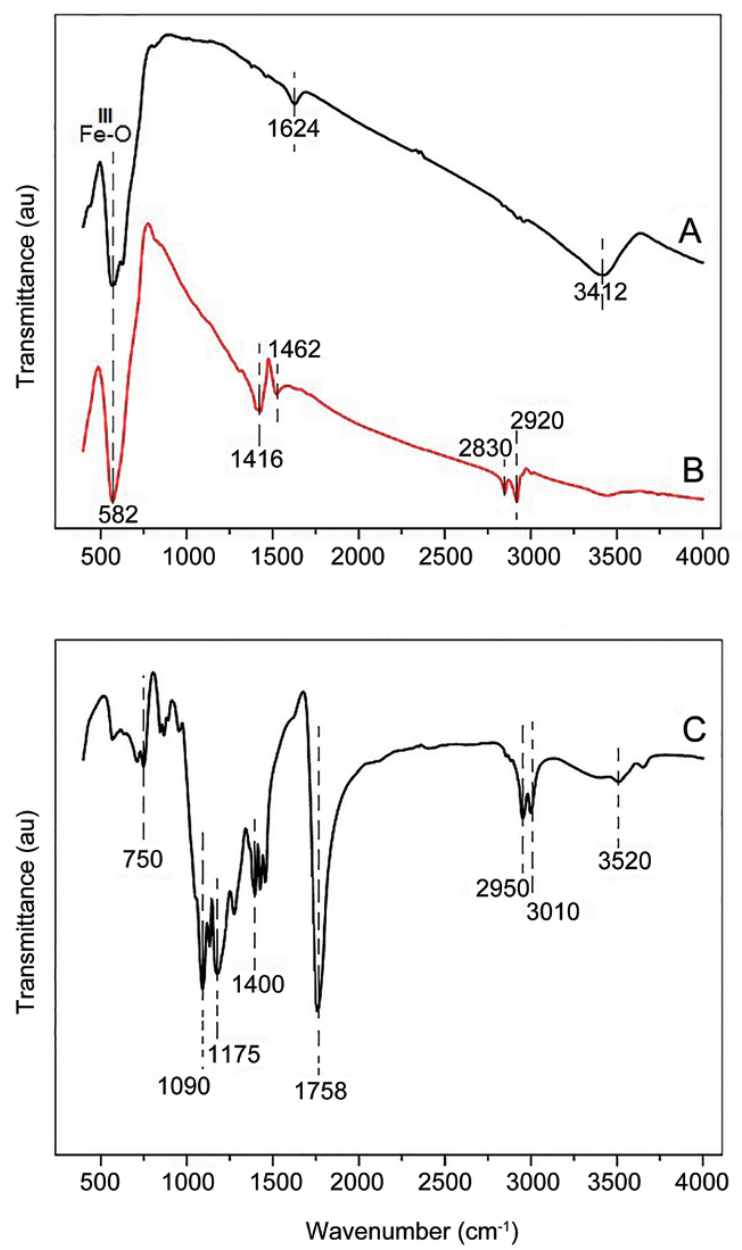

Figure 4. FTIR spectra of (A) MNP, (B) OA-MNP and (C) MNP-PLGA NPs.

indicates the presence of ferric hydroxide in the MNP. For OA-MNP, the absorption bands at 1416 and $1520 \mathrm{~cm}^{-1}$ are due to the symmetric and asymmetric stretching vibrations of $\mathrm{CH}_{3}$, respectively. The absorption bands at 2830 and $2920 \mathrm{~cm}^{-1}$ are due to the symmetric and asymmetric stretching vibrations of $-\mathrm{CH}$, respectively. Owing to the interaction between PLGA and OA-MNP, the symmetric vibrations of $-\mathrm{CH}$ for MNPPLGA NPs were shifted to 2950 and $3010 \mathrm{~cm}^{-1}$. These observations are consistent with reported results ${ }^{[32]}$.

\section{Encapsulation efficiency and drug release}

The encapsulation efficiency and drug release of PTX for MNP-PLGA NPs with and without Tf modification were studied (Table 1). Here, the Tf-modified PTX-MNP-PLGA NPs were synthesized with a Tf concentration of $1.0 \mathrm{mg} / \mathrm{mL}$. The encapsulation efficiencies of PTX in MNP-PLGA NPs with and without Tf modification were $82.9 \%$ and $87.3 \%$, respectively. The release profiles of PTX from MNP-PLGA NPs with and without Tf modification were observed to be similar (Figure 5). More than $80 \%$ of the drug was released within a period of $10 \mathrm{~d}$. The release of PTX from PLGA NPs followed a biphasic profile, with a rapid drug release rate during the initial phase
Table 1. Encapsulation efficiency (EE) of PTX in different samples.

\begin{tabular}{lcc}
\hline Samples & PTX-MNP-PLGA NPs & Tf-modified PTX-MNP-PLGA NPS \\
\hline EE & $87.3 \%$ & $82.9 \%$ \\
\hline
\end{tabular}

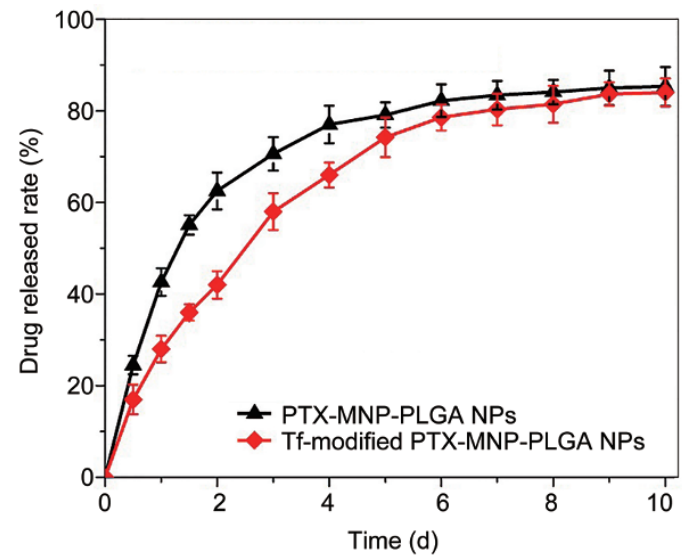

Figure 5. In vitro release profiles of PTX from PTX-MNP-PLGA NPs and Tfmodified PTX-MNP-PLGA NPs.

of incubation followed by a slow release.

\section{In vitro cytotoxicity}

The in vitro cytotoxicity of drug-loaded NPs in MCF-7 and U-87 cells was examined to determine their therapeutic efficiency (Figure 6). Here, PTX was selected as the model drug to evaluate the potential of Tf-modified MNP-PLGA NPs as a tumor-targeting nanocarrier for hydrophobic drugs ${ }^{[34,35]}$. For both MCF-7 and U-87 cells, the Tf-modified PTX-MNP-PLGA NPs showed the highest cytotoxicity effect, followed by Tfmodified NPs with free Tf, unmodified NPs and free PTX (Figure 6). Compared to the unmodified NPs, the Tf-modified PTX-MNP-PLGA NPs enhanced cellular uptake and increased cell cytotoxicity. However, in the presence of free Tf, the Tfmodified PTX-MNP-PLGA NPs showed a lower cytotoxicity effect. This may be attributed to the competition between Tfmodified PLGA NPs and free Tf for cellular uptake, which would in turn lower the cytotoxicity of Tf-modified PLGA NPs. Finally, the free PTX showed the lowest cytotoxicity effect relative to other NP formulations. In this case, the drugresistant tumor cells could prevent intracellular accumulation of the free drug despite the high drug concentration used.

\section{In vitro cellular uptake}

The cellular uptake of drug-loaded NPs in MCF-7 and U-87 cells was examined by laser scanning confocal microscopy (Figure 7 and 8). To visualize the drug distribution within the cells, PTX was replaced by CM. Overall, CM was found mainly in the cytosol and around the nucleus, indicating that CM-MNP-PLGA NPs were successfully taken up by the cells. Cells treated with Tf-modified CM-MNP-PLGA NPs showed 

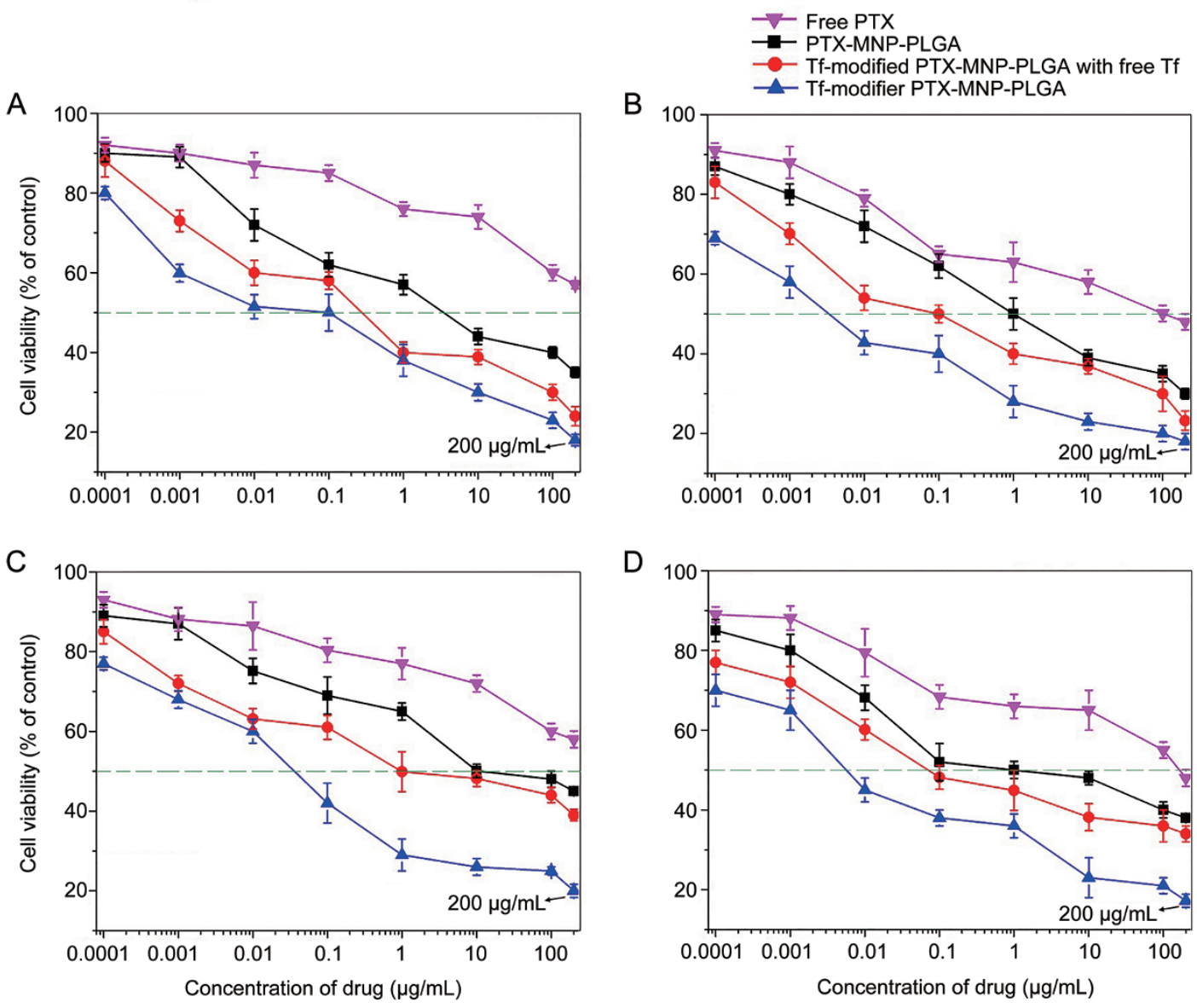

Figure 6. Viability of (A and B) MCF-7 and ( $C$ and D) U-87 cells after treatment with Tf-modified PTX-MNP-PLGA NPs, Tf-modified PTX-MNP-PLGA NPs with free Tf, PTX-MNP-PLGA NPs and free PTX for (A and C) $24 \mathrm{~h}$ and (B and D) $96 \mathrm{~h}$.

greater fluorescence intensity than those treated with free Tf, unmodified NPs or free CM. Thus, Tf-modified NPs could lead to higher cellular uptake and hence greater drug accumulation. These confocal images are consistent with the cytotoxcity results reported earlier.

To support the qualitative analysis from the confocal images, the cellular uptake of drug-loaded NPs was quantified by measuring the percentage of drug internalized by the cells (Figure 9A and 9B). For both MCF-7 and U-87 cells, the uptake of CM or PTX was the highest for Tf-modified MNPPLGA NPs, further verifying that the presence of Tf on the surface of PLGA NPs can trigger receptor-mediated endocytosis and result in enhanced intracellular delivery of drugs ${ }^{[36]}$. The cellular uptake of drug-loaded NPs was also quantified in the presence of an applied magnetic field (Figure 9C). The cellular uptake efficiency of MNP-PLGA NPs seemed to be slightly greater in the presence of a magnetic field than in a non-magnetic condition; however, this effect did not reach statistical significance.

\section{Discussion}

Polymeric NPs modified with targeting ligands have attracted significant attention in the biomedical field because of their ability to enhance intracellular delivery and provide sustained drug release ${ }^{[37,38]}$. Since the efficacy of chemotherapy is severely hindered by low drug accumulation in tumor cells, Tf-modified PLGA NPs that target the Tf receptors of tumors could improve the treatment of cancer. In this study, PTX (a potent antineoplastic agent) and MNP (for magnetic fieldmediated delivery) were loaded into PLGA NPs via a solidin-oil-in-water solvent evaporation process (Scheme 1A). Magnetically targeted nanodrug delivery systems have great potential for precise delivery of drugs under an applied magnetic field. Here, the MNP-PLGA NPs exhibited a superparamagnetic property (Figure $2 \mathrm{~A}-2 \mathrm{C}$ ), which was good enough to orient them to the target site and enhance the cellular uptake efficiency via an applied magnetic field. In other words, the Tf-modified magnetic PLGA NPs could have some advantages through their delivery of chemotherapeutics to the target location in the body and, consequently, reducing normal tissue toxicity.

To improve the stability of the system, amphiphilic PVA was added to stabilize the emulsified droplets by minimizing the coalescence and aggregation of newly formed NPs in the aqueous phase during the synthesis process. Moreover, amphiphilic PVA could enhance the encapsulation of MNP 
A

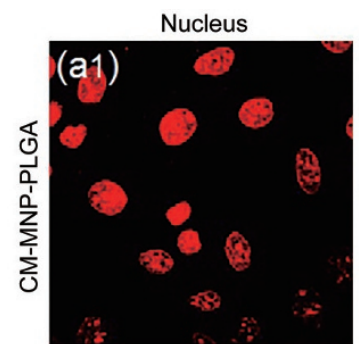

B

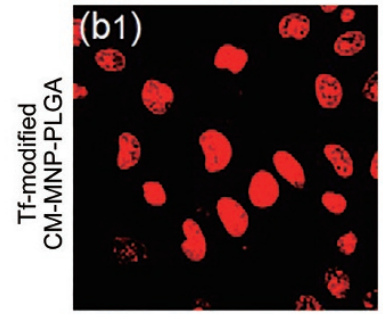

C

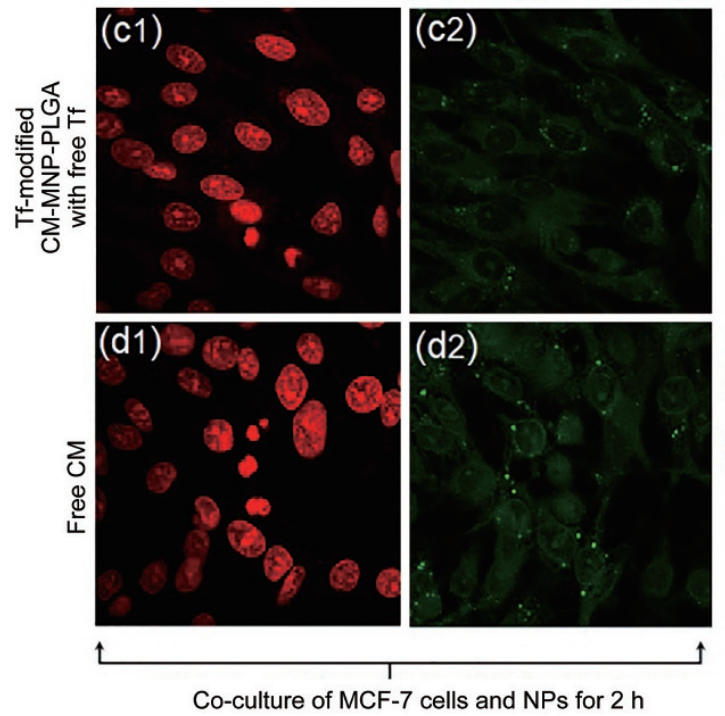

$\mathrm{CM}$
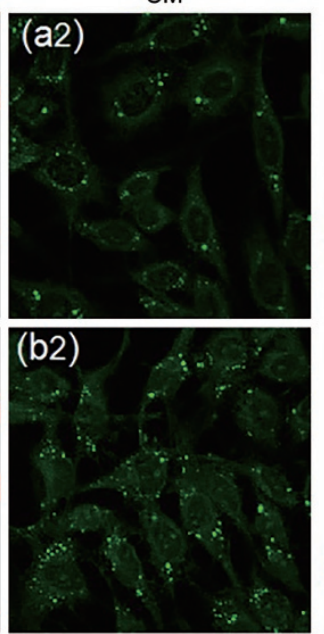

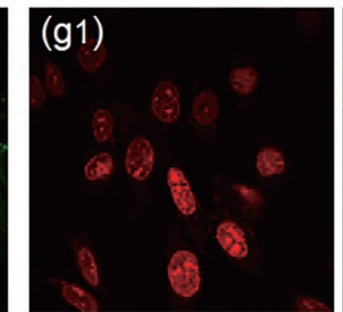

Co-culture of MCF-7 cells and NPs for $8 \mathrm{~h}$ (h1)

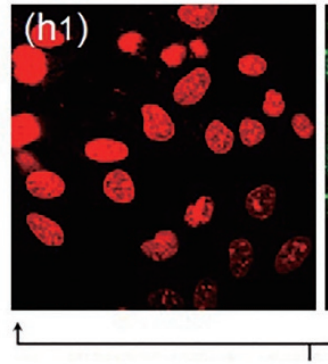

$\mathrm{CM}$
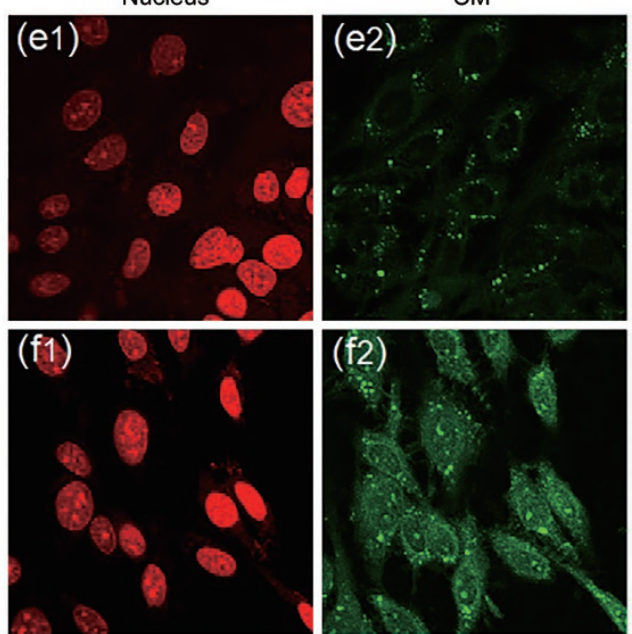

(g2)

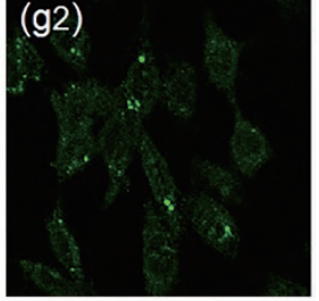

(h2)

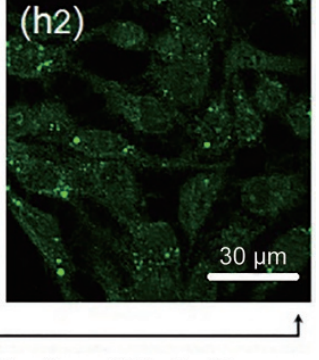

$\uparrow$

Figure 7. Confocal images depicting cellular uptake and drug distribution of (A) CM-MNP-PLGA NPs, (B) Tf-modified CM-MNP-PLGA NPs, (C) Tf-modified CM-MNP-PLGA NPs with free Tf, and (D) free CM in MCF-7 cells after $(\mathrm{a}-\mathrm{d}) 2 \mathrm{~h}$ and $(\mathrm{e}-\mathrm{h}) \mathrm{g} \mathrm{h}$ of incubation. The red shows the cell nuclei while the green shows the presence of $\mathrm{CM}$.

into the polymeric nanoparticles via hydrophobic interactions. It has also been reported ${ }^{[39,40]}$ that the concentration of PVA could influence the size of the NPs during preparation via the emulsion solvent evaporation method. However, as seen from TEM images, the NPs showed negligible particle size difference after using a high concentration $[4 \%(w / v)]$ and a low concentration $[2 \%(w / v)]$ of PVA solution (Figure 1). The surface of MNP-PLGA NPs was also modified with Tf via adsorption (Scheme 1B), and the presence of Tf was verified (Figure 3B). Surface modification of MNP-PLGA NPs with Tf did not significantly influence the encapsulation efficiency and drug release profile.

The effective cytotoxicity of Tf-modified MNP-PLGA NPs mainly depended on the amount of encapsulated chemotherapeutic drugs, the release behaviors of the encapsulated chemotherapeutic drugs and the cellular uptake efficiency. First, the Tf-modified MNP-PLGA NPs showed a similar encapsulation efficiency for PTX as the unmodified NPs, which was helped to some extent by a high drug concentration. Second, the release of PTX from Tf-modified MNP-PLGA NPs exhibited a two-phase pattern: an initial rapid release in the first $4 \mathrm{~d}$, followed by a relaxed slow release in the following days. The releasing property could depend on three dominating mechanisms: diffusion, swelling and degradation. Both the structure and size of the PLGA NPs could also impact the release profile. Third, drug-loaded NPs with Tf as the targeting ligand can enhance cellular uptake, provide greater internal drug release and promote a higher cytotoxicity effect (Scheme $1 C)^{[35,41]}$. The results indicated that the Tf-modified PTX-MNPPLGA NPs exhibited the highest cytotoxicity effect, followed by the Tf-modified NPs with free Tf, the unmodified NPs and the free PTX (Figure 6). The cellular uptake of drug-loaded NPs in MCF-7 and U-87 cells was examined by laser scanning confocal microscopy (Figure 7 and 8). The Tf-modified CM- 

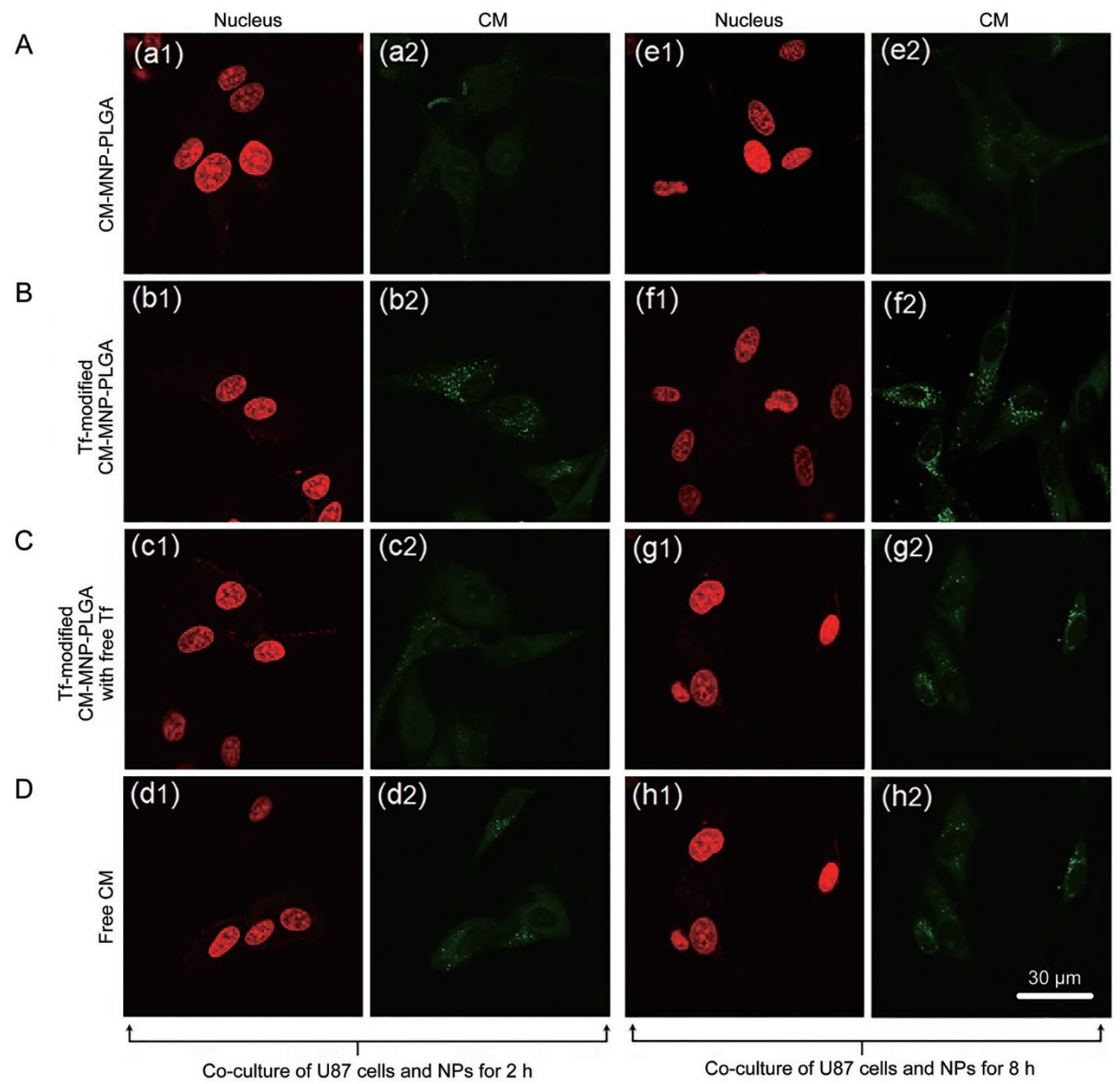

Figure 8. Confocal images depicting cellular uptake and drug distribution of (A) CM-MNP-PLGA NPs, (B) Tf-modified CM-MNP-PLGA NPs, (C) Tf-modified CM-MNP-PLGA NPs with free Tf, and (D) free CM in U-87 cells after $(\mathrm{a}-\mathrm{d}) 2 \mathrm{~h}$ and $(\mathrm{e}-\mathrm{h}) 8 \mathrm{~h}$ of incubation. The red shows the cell nuclei while the green shows the presence of $\mathrm{CM}$.

MNP-PLGA NPs showed the highest intracellular accumulation, with most of the NPs clustering in the cytosol and around the nucleus. Additional consistent results were obtained by quantitative measurement of the percentage of drug internalized by the cells (Figure 9A and 9B). The cellular uptake efficiency of MNP-PLGA NPs seemed to be slightly greater in the presence of a magnetic field than in a non-magnetic condition; however, the difference was not statistically significant (Figure 9C). These Tf-targeting carriers could achieve higher cellular uptake efficiency, mainly because of their recognition of $\mathrm{Tf}$ receptors that are overexpressed in MCF-7 breast cancer and U-87 glioma cells ${ }^{[42]}$. Moreover, Tf could surmount the drug resistance owing to membrane-associated drug resistance proteins such as P-glycoprotein ${ }^{[43]}$.

\section{Conclusions}

In this study, Tf-modified MNP-PLGA NPs were successfully synthesized and characterized, and their cellular uptake efficiencies in MCF-7 breast cancer and U-87 glioma cells were demonstrated through receptor- and magnetic field-mediated delivery. Compared to unmodified NPs or free PTX, Tfmodified PTX-MNP-PLGA NPs demonstrated the highest cellular uptake efficiency and greatest antiproliferative effect on MCF-7 and U-87 cells. Overall, Tf-modified MNP-PLGA NPs are suitable drug carriers for the treatment of cancer.

\section{Acknowledgements}

The authors acknowledge the funding support from the National University of Singapore (NUS) (R279-000-357-275), the National Medical Research Council (NMRC, Singapore) (NMRC/EDG11may084), and the National Natural Science Foundation of China (81402885). Yan-na CUI also acknowledges the Chinese Scholarship Council for supporting her PhD program during her exchange at NUS. 


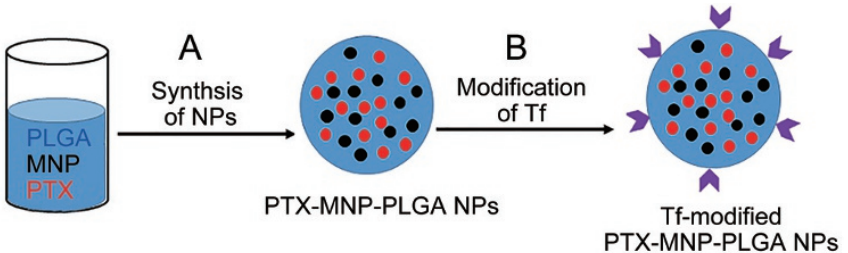

C Endocytosis and subsequent intracellular release of PTX

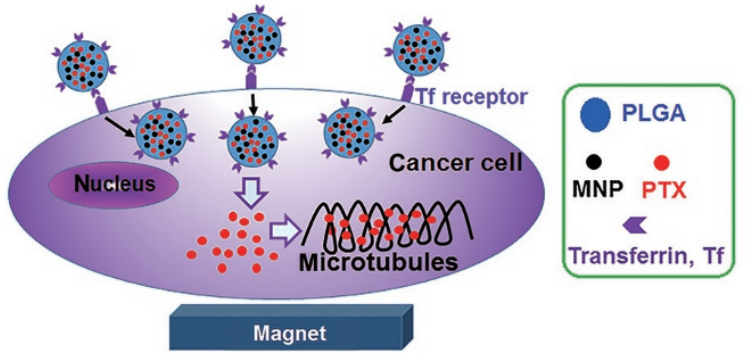

Scheme 1. Synthesis of Tf-modified PTX-MNP-PLGA NPs via (A) solidin-oil-in-water solvent evaporation process and (B) Tf adsorption on the surface of NPs. (C) Endocytosis of Tf-modified PTX-MNP-PLGA NPs and subsequent intracellular release of PTX.

\section{Author contribution}

Yan-na CUI performed the experiments, analyzed the data, prepared the figures and wrote the manuscript; Qing-xing XU and Pooya DAVOODI revised the manuscript and figures; Deping WANG and Chi-Hwa WANG designed the study and supervised the team. The authors have read and approved the final version of the manuscript.

\section{References}

1 Luan X, Guan YY, Lovell JF, Zhao M, Lu Q, Liu YR. Tumor priming using metronomic chemotherapy with neovasculature-targeted, nanoparticulate paclitaxel. Biomaterials 2016; 95: 60-73.

2 Kareva I, Waxman DJ, Lakka Klement G. Metronomic chemotherapy: an attractive alternative to maximum tolerated dose therapy that can activate anti-tumor immunity and minimize therapeutic resistance. Cancer Lett 2015; 358: 100-6.

3 Holmes FA, Walters RS, Theriault RL, Forman AD, Newton LK, Raber $\mathrm{MN}$, et al. Phase II trial of taxol, an active drug in the treatment of metastatic breast cancer. J Natl Cancer Inst 1991; 83: 1797-805.

4 McGuire WP, Rowinsky EK, Rosenshein NB, Grumbine FC, Ettinger DS, Armstrong DK, et al. Taxol: a unique antineoplastic agent with significant activity in advanced ovarian epithelial neoplasms. Ann Intern Med 1989; 111: 273-9.

5 Rowinsky EK, Wright M, Monsarrat B, Lesser GJ, Donehower RC. Taxol: pharmacology, metabolism and clinical implications. Cancer Surv 1993; 17: 283-304.

6 Cirstoiu-Hapca A, Buchegger F, Bossy L, Kosinski M, Gurny R, Delie F. Nanomedicines for active targeting: physico-chemical characterization of paclitaxel-loaded anti-HER2 immunonanoparticles and in vitro functional studies on target cells. Eur J Pharm Sci 2009; 38: 230-7.

7 Zhang W, Shi Y, Chen Y, Ye J, Sha X, Fang X. Multifunctional Pluronic P123/F127 mixed polymeric micelles loaded with paclitaxel for the treatment of multidrug resistant tumors. Biomaterials 2011; 32 : 2894-906.
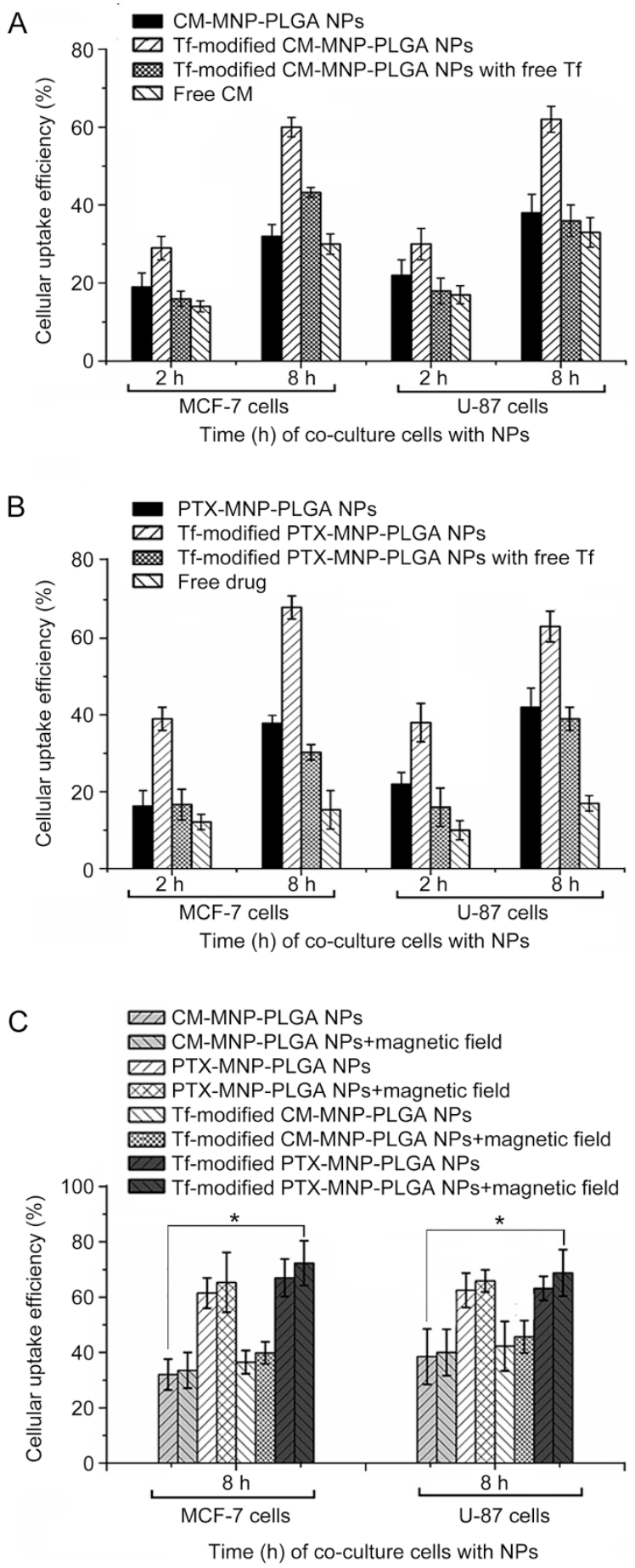

Figure 9. Cellular uptake efficiency of (A) CM-loaded PLGA NPs and (B) PTX-loaded PLGA NPs in MCF-7 and U-87 cells after 2 and $8 \mathrm{~h}$ of incubation in the absence of a magnetic field. (C) Comparison of cellular uptake efficiencies of drug-loaded PLGA NPs after $8 \mathrm{~h}$ of incubation in the presence of a magnetic field. ${ }^{*} P<0.05$.

8 Lee Y, Graeser R, Kratz F, Geckeler KE. Paclitaxel-loaded polymer nanoparticles for the reversal of multidrug resistance in breast cancer cells. Adv Funct Mater 2011; 21: 4211-8.

9 Lehnert M. Clinical multidrug resistance in cancer: a multifactorial problem. Eur J Cancer 1996; 32A: 912-20. 
10 Danhier F, Ansorena E, Silva JM, Coco R, Le Breton A, Préat V. PLGAbased nanoparticles: an overview of biomedical applications. J Control Release 2012; 161: 505-22.

11 Guo J, Gao X, Su L, Xia H, Gu G, Pang Z, et al. Aptamer-functionalized PEG-PLGA nanoparticles for enhanced anti-glioma drug delivery. Biomaterials 2011; 32: 8010-20.

12 Li J, Feng L, Fan L, Zha Y, Guo L, Zhang Q, et al. Targeting the brain with PEG-PLGA nanoparticles modified with phage-displayed peptides. Biomaterials 2011; 32: 4943-50.

13 Mahmoudi M, Simchi A, Imani M, Milani AS, Stroeve P. Optimal design and characterization of superparamagnetic iron oxide nanoparticles coated with polyvinyl alcohol for targeted delivery and imaging. J Phys Chem B 2008; 112: 14470-81.

14 Laurent S, Mahmoudi M. Superparamagnetic iron oxide nanoparticles: promises for diagnosis and treatment of cancer. Int J Mol Epidemiol Genet 2011; 2: 367-90.

15 Wahajuddin, Arora S. Superparamagnetic iron oxide nanoparticles: magnetic nanoplatforms as drug carriers. Int J Nanomedicine 2012; 7: 3445-71.

16 Polyak B, Friedman G. Magnetic targeting for site-specific drug delivery: applications and clinical potential. Expert Opin Drug Deliv 2009; 6: 53-70.

17 McCarron PA, Marouf WM, Donnelly RF, Scott C. Enhanced surface attachment of protein-type targeting ligands to poly(lactide-coglycolide) nanoparticles using variable expression of polymeric acid functionality. J Biomed Mater Res A 2008; 87: 873-84.

18 Zhang N, Chittasupho C, Duangrat C, Siahaan TJ, Berkland C. PLGA nanoparticle-peptide conjugate effectively targets intercellular celladhesion molecule-1. Bioconjug Chem 2008; 19: 145-52.

19 Aravind A, Jeyamohan P, Nair R, Veeranarayanan S, Nagaoka Y, Yoshida $\mathrm{Y}$, et al. AS1411 aptamer tagged PLGA-lecithin-PEG nanoparticles for tumor cell targeting and drug delivery. Biotechnol Bioeng 2012; 109: 2920-31.

20 Wu XL, Kim JH, Koo H, Bae SM, Shin H, Kim MS, et al. Tumor-targeting peptide conjugated $\mathrm{pH}$-responsive micelles as a potential drug carrier for cancer therapy. Bioconjug Chem 2010; 21: 208-13.

21 Yue J, Liu S, Mo G, Wang R, Jing X. Active targeting and fluorescencelabeled micelles: preparation, characterization and cellular uptake evaluation. J Control Release 2011; 152: e258-60.

22 Zhang P, Hu L, Yin Q, Feng L, Li Y. Transferrin-modified c[RGDfK]paclitaxel loaded hybrid micelle for sequential blood-brain barrier penetration and glioma targeting therapy. Mol Pharm 2012; 9: 1590-8.

23 Pang Z, Gao H, Yu Y, Guo L, Chen J, Pan S, et al. Enhanced intracellular delivery and chemotherapy for glioma rats by transferrinconjugated biodegradable polymersomes loaded with doxorubicin. Bioconjug Chem 2011; 22: 1171-80.

24 Kuo YC, Lin PI, Wang CC. Targeting nevirapine delivery across human brain microvascular endothelial cells using transferrin-grafted poly(lactide-co-glycolide) nanoparticles. Nanomedicine 2011; 6: 1011-26.

25 Chang J, Paillard A, Passirani C, Morille M, Benoit JP, Betbeder D, et al. Transferrin adsorption onto PLGA nanoparticles governs their interaction with biological systems from blood circulation to brain cancer cells. Pharm Res 2012; 29: 1495-505.

26 Ramírez LP, Landfester K. Magnetic polystyrene nanoparticles with a high magnetite content obtained by miniemulsion processes. Macromol Chem Phys 2003; 204: 22-31.
27 Jain TK, Morales MA, Sahoo SK, Leslie-Pelecky DL, Labhasetwar V. Iron oxide nanoparticles for sustained delivery of anticancer agents. Mol Pharm 2005; 2: 194-205.

28 Liu X, Kaminski MD, Chen H, Torno M, Taylor L, Rosengart AJ. Synthesis and characterization of highly-magnetic biodegradable poly(d,I-lactide-co-glycolide) nanospheres. J Control Release 2007; 119: 52-8.

29 Chang J, Jallouli Y, Kroubi M, Yuan XB, Feng W, Kang CS, et al. Characterization of endocytosis of transferrin-coated PLGA nanoparticles by the blood-brain barrier. Int J Pharm 2009; 379: 285-92.

30 Gan CW, Feng SS. Transferrin-conjugated nanoparticles of poly(lactide)-D-alpha-tocopheryl polyethylene glycol succinate diblock copolymer for targeted drug delivery across the blood-brain barrier. Biomaterials 2010; 31: 7748-57.

31 Banquy X, Suarez F, Argaw A, Rabanel JM, Grutter P, Bouchard JF, et al. Effect of mechanical properties of hydrogel nanoparticles on macrophage cell uptake. Soft Matter 2009; 5: 3984-91.

32 Andhariya N, Chudasama B, Mehta RV, Upadhyay RV. Biodegradable thermoresponsive polymeric magnetic nanoparticles: a new drug delivery platform for doxorubicin. J Nanopart Res 2011; 13: 167788.

33 Liu Q, Zhang J, Xia W, Gu H. Magnetic field enhanced cell uptake efficiency of magnetic silica mesoporous nanoparticles. Nanoscale 2012; 4: 3415-21.

34 Scripture CD, Figg WD, Sparreboom A. Paclitaxel chemotherapy: from empiricism to a mechanism-based formulation strategy. Ther Clin Risk Manag 2005; 1: 107-14.

35 Zhang P, Hu L, Yin Q, Zhang Z, Feng L, Li Y. Transferrin-conjugated polyphosphoester hybrid micelle loading paclitaxel for brain-targeting delivery: synthesis, preparation and in vivo evaluation. J Control Release 2012; 159: 429-34.

36 Li SD, Huang L. Pharmacokinetics and biodistribution of nanoparticles. Mol Pharm 2008; 5: 496-504.

$37 \mathrm{Li} \mathrm{Y,} \mathrm{He} \mathrm{H,} \mathrm{Jia} \mathrm{X,} \mathrm{Lu} \mathrm{WL,} \mathrm{Lou} \mathrm{J,} \mathrm{Wei} \mathrm{Y.} \mathrm{A} \mathrm{dual-targeting} \mathrm{nanocarrier}$ based on poly(amidoamine) dendrimers conjugated with transferrin and tamoxifen for treating brain gliomas. Biomaterials 2012; 33 : 3899-908.

38 Xin H, Sha X, Jiang X, Zhang W, Chen L, Fang X. Anti-glioblastoma efficacy and safety of paclitaxel-loading Angiopep-conjugated dual targeting PEG-PCL nanoparticles. Biomaterials 2012; 33: 8167-76.

39 Guo H, Yang D, Yang M, Gao Y, Liu Y, Li H. Dual responsive pickering emulsions stabilized by constructed core crosslinked polymer nanoparticles via reversible covalent bonds. Soft Matter 2016; 12: 968391.

40 Bohrey S, Chourasiya V, Pandey A. Polymeric nanoparticles containing diazepam: preparation, optimization, characterization, in-vitro drug release and release kinetic study. Nano Converg 2016; 3: 3.

41 Sahoo SK, Labhasetwar V. Enhanced antiproliferative activity of transferrin-conjugated paclitaxel-loaded nanoparticles is mediated via sustained intracellular drug retention. Mol Pharm 2005; 2: 373-83.

42 Lu C, Xing MMQ, Zhong W. Shell cross-linked and hepatocytetargeting nanoparticles containing doxorubicin via acid-cleavable linkage. Nanomedicine 2011; 7: 80-7.

43 Wang F, Jiang X, Yang DC, Elliott RL, Head JF. Doxorubicin-galliumtransferrin conjugate overcomes multidrug resistance: evidence for drug accumulation in the nucleus of drug resistant MCF-7/ADR cells. Anticancer Res 2000; 20: 799-808. 